\title{
Immobilization and Stabilization of Enzyme in Biomineralized Calcium Carbonate Microspheres
}

\section{OPEN ACCESS}

Edited by:

Roland Wohlgemuth,

Lodz University of Technology, Poland

Reviewed by:

Dirk Tischler,

Ruhr University Bochum, Germany

Quanshun Li,

Jilin University, China

Bogdan Parakhonskiy,

Ghent University, Belgium

*Correspondence:

Ee Taek Hwang

ethwang@dau.ac.kr

Jin Hyung Lee

leejinh1@kicet.re.k

Specialty section:

This article was submitted to

Bioprocess Engineering

a section of the journal

Frontiers in Bioengineering and

Biotechnology

Received: 19 April 2020

Accepted: 18 September 2020

Published: 09 October 2020

Citation:

Lee $\mathrm{CH}$, Jin ES, Lee JH and

Hwang ET (2020) Immobilization

and Stabilization of Enzyme

in Biomineralized Calcium Carbonate

Microspheres.

Front. Bioeng. Biotechnol. 8:553591.

doi: 10.3389/fbioe.2020.553591

\author{
Chan Hee Lee ${ }^{1,2}$, Eon Seon Jin', Jin Hyung Lee ${ }^{2 *}$ and Ee Taek Hwang ${ }^{3 *}$ \\ ${ }^{1}$ Department of Life Science, Research Institute for Nature Sciences, Hanyang University, Seoul, South Korea, ${ }^{2}$ Center for \\ Convergence Bioceramic Materials, Korea Institute of Ceramic Engineering and Technology, Cheongju-si, South Korea, \\ ${ }^{3}$ Department of Food Biotechnology, Dong-A University, Busan, South Korea
}

Biomineralized uniform and well-organized calcium carbonate microspheres were synthesized for enzyme immobilization, and the immobilized enzyme was successfully stabilized. The physicochemical parameters of calcium carbonate were studied using scanning electron microscopy with energy-dispersive X-ray spectroscopy, particle size analysis, X-ray diffraction analysis, Fourier-transform infrared spectroscopy, and surface area measurement. Additionally, Barrett-Joyner-Halenda adsorption/desorption analysis showed that the calcium carbonate microspheres provided efficient mesopore space for enzyme loading. As a model enzyme, carboxyl esterase (CE) was entrapped and then cross-linked to form an enzyme structure. In this aggregate, the cross-linked enzymes cannot leach out from mesopores, resulting in enzyme stability. The hydrolytic activities of the free and cross-linked enzymes were analyzed over broad temperature and $\mathrm{pH}$ ranges. The cross-linked enzyme displayed better activity than the free enzyme. Furthermore, the immobilized CE was found to be stable for more than 30 days, preserving $60 \%$ of its initial activity even after being reused more than 10 times. This report is expected to be the first demonstration of a stabilized cross-linked enzyme system in calcium carbonate microspheres, which can be applied in enzyme catalyzed reactions involved in bioprocessing, bioremediation, and bioconversion.

Keywords: enzyme immobilization, enzyme stabilization, biomineralization, calcium carbonate, cross-linking

\section{INTRODUCTION}

Enzymes are proteins that catalyze chemical reactions, reducing the initial energy input, by increasing the reaction rate. Based on enzyme processes relevant to environment-friendly features used in chemical transformation, enzymes are widely utilized in various fields such as food, pharmaceuticals, biodiesel, and biofuels (Datta et al., 2013; Hwang and Gu, 2013; Jesionowski et al., 2014). Additionally, enzymes usually function under mild conditions such as ambient temperature and pressure. Therefore, industrial applications of enzymes are increasing (Schoemaker et al., 2003). In industrial processes, free enzymes are destabilized, and it is difficult to reuse them efficiently (Iyer and Ananthanarayan, 2008). Enzyme immobilization allows overcoming this drawback by improving enzyme reactivity and stability (Mateo et al., 2007; Hanefeld et al., 2009). Immobilization of an enzyme can prevent it from structural denaturation caused by the external environment; thus, enzyme activity can be maintained from various reaction conditions by preserving storage stability. 
Besides, the immobilized enzyme can be easily separated from the reaction solution, and it can be easily washed and reused after measuring the activity (Hwang et al., 2012a, 2013).

Enzyme immobilization methods include physical adsorption, ionic and covalent bonds, and various techniques such as binding, entrapment, encapsulation, and cross-linking. Enzymes can be immobilized on various organic and inorganic materials or carriers. Synthetic organic polymeric beads such as Sepabeads and Amberlite; a variety of biopolymers, mainly water-insoluble polysaccharides such as cellulose, starch, agarose, alginate, chitosan, and electrospun nanofibers; and polymeric membranes are widely used as supports for immobilizing enzymes (Cantone et al., 2013; Hwang and Gu, 2013; Zdarta et al., 2018; RodriguezAbetxuko et al., 2020). Inorganic materials such as silica, magnetic particles, inorganic oxides, clay, and graphene oxide have been used for enzyme immobilization (Wang et al., 2014; Zucca and Sanjust, 2014; Wu et al., 2015; Xia et al., 2020). Among these, mesoporous materials have been applied to accommodate enzymes and maintain their activity in the pore space, owing to their pore size, connectivity, and high stability (Wang and Caruso, 2004; Xu et al., 2019). However, simple adsorption or entrapment into the pore space leads to rapid release from the pores, and reduces stability (Hwang et al., 2012b; Li and Wang, 2013).

To prevent the release of enzymes from mesoporous materials and improve stability, the cross-linking method is used (Kim et al., 2007). Cross-linking can be achieved via physicochemical methods such as heat treatment, application of alkaline conditions, mechanical agitation, photo-oxidation treatment, and the use of chemical reagents with an enzyme catalyst (Heck et al., 2013). A simple chemical reagent, glutaraldehyde (GA), is most widely used in biocatalyst design, and is the most powerful cross-linker (Barbosa et al., 2014). It has the advantage of self-reaction. Owing to the successful application of enzymeimmobilizing carriers, mesoporous silica has been widely used. However, for preparation, the high cost of the process (heat and solvent), mechanical stability under base conditions, size control, use of toxic silica precursors, and aggregation during the drying step can be disadvantages for its simple application in enzyme immobilization studies. Contrary to the several weaknesses of mesoporous silica, the advantages of calcium carbonate make it a good alternative enzyme immobilization carrier (Hwang et al., 2012a; Binevski et al., 2019). It can be used as an adsorbent or template, and synthesized as spheres with various particle sizes (Gower, 2008; Hwang et al., 2013). Moreover, it is suitable for living organisms because it is natural, non-toxic, and stable (Fakhrullin and Minullina, 2009). Furthermore, calcium carbonate is cheap, eco-friendly, and easy to synthesize with a simple scale-up process, in addition to being stable even under basic conditions (Binevski et al., 2019). Calcium carbonate and calcium carbonate-modified materials have previously been used in enzyme studies as immobilizing carriers and delivery vehicles. For example, several attempts have been made to encapsulate enzymes such as superoxide dismutase, alkaline phosphatase, pyruvate kinase, and lactate dehydrogenase and characterize the encapsulated enzyme in terms of the enzyme loading and efficiency, specific activity, and change in activity based on the morphological changes of calcium carbonate (Donatan et al., 2016; Muderrisoglu et al., 2018; Binevski et al., 2019). Additionally, the release behavior from the calcium carbonate particles has also been investigated (Roth et al., 2018; Abalymov et al., 2020). However, these studies did not focus on the stabilized enzyme system in calcium carbonate particles, the most important compound in industrial enzymatic bioconversion. In pharmaceutical and fine chemical industries, bioconversion processes necessitate a specific reactor design and enzyme activity for effective execution of the enzymatic processes.

Therefore, as a model study, we investigated enzyme stabilization by immobilizing carboxyl esterase (CE) from Rhizopus oryzae into the pores of biomineral calcium carbonate microspheres. Biomineralized calcium carbonate can be synthesized as a well-formulated uniform carrier. First, Biomineralized calcium carbonate can be synthesized into well formulated uniform carrier; The prepared mesoporous spherical calcium carbonate microspheres with a size of $5.5 \pm 1.8 \mu \mathrm{m}$ were fully characterized using scanning electron microscopy (SEM). Energy-dispersive X-ray spectroscopy (EDS), particle size analyzer (PSA), X-ray diffraction (XRD), Fourier-transform infrared spectroscopy (FT-IR). Additionally, Brunauer-EmmettTeller (BET) was used to analyze the surface area, pore volume, adsorption pore size, and desorption pore size. First, the CE was adsorbed inside of the prepared calcium carbonate and then cross-linked by treatment with GA to design stabilized enzyme structures. It was found that the activity was preserved for 30 days; the catalytic activity was stable even after 10 reuses, exhibiting high storage stability and recyclability. This study gives the applications of a stable and recyclable cross-linked enzyme in calcium carbonate microspheres and will contribute to practical enzyme-based process applications.

\section{MATERIALS AND METHODS}

\section{Materials}

Calcium chloride (Sigma), ammonium carbonate (Sigma), sodium phosphate monobasic (Sigma), sodium phosphate dibasic (Sigma), N,N-dimethylformamide (DMF) (Sigma), and Tris-HCl (1 M, Bioneer, Alameda CA, United States) were purchased. The model enzyme $\mathrm{CE}$ from Rhizopus oryzae (Sigma) was used for immobilization, and the substrate p-nitrophenyl butyrate (Sigma) was purchased from SigmaAldrich. $p$-nitrophenol (Sigma) was used for the standard curve for products by enzymatic reaction. Finally, a BCA protein assay kit (Pierce, Rockford, IL, United States) for measuring enzyme loading was purchased from Sigma.

\section{Synthesis of Calcium Carbonate Microspheres}

To synthesize biomineralized calcium carbonate microspheres, $200 \mathrm{mM}$ of $\mathrm{CaCl}_{2}$ solution (distilled water:acetone $=5: 1$ ) was mixed for dissolution. $\left(\mathrm{Na}_{4}\right)_{2} \mathrm{CO}_{3}$ solution $(200 \mathrm{mM})$ was added to $\mathrm{CaCl}_{2}$ solution with vigorous stirring for $10 \mathrm{~min}$. After synthesis, the sample was washed twice with ethanol to remove 
solution and then dried at $60^{\circ} \mathrm{C}$ in a dry oven. After drying, the powder samples were collected and stored at room temperature.

\section{Characterization of $\mathrm{CaCO}_{3}$ Microspheres}

The morphological and elemental analysis of $\mathrm{CaCO}_{3}$ microspheres was performed using FE-SEM equipped with energy-dispersive X-ray spectroscopy (EDAX) (TESCAN, Czech Republic). Pt sputtered coating was done before SEM analysis. BET surface area and pore size were obtained using a Tristar II (Micromeritics, United States). Pore-size distributions and pore volume were calculated using the Barett-JoynerHalenda equation. FT-IR analysis was performed using an FT-IR spectrometer (Jasco, United States) range of $650-4000 \mathrm{~cm}^{-1}$. XRD patterns were analyzed by a Rigaku Mini Flex 600 (Rigaku, Japan) using $\mathrm{Cu} \mathrm{K} \alpha$ radiation $(\lambda=1.5418 \AA$ ) at scanning rate of $5.00^{\circ} \mathrm{min}^{-1}$. Particle size analysis was performed using laser scatter particle size distribution analyzer LA-960 (Horiba, Japan).

\section{Enzyme Immobilization}

Immobilization of the enzyme into the calcium carbonate pores was performed via two-step process. First, $1.5 \mathrm{~mL}$ CE solution $(0.66 \mathrm{mg} / \mathrm{mL})$ was added to a glass vial containing $10 \mathrm{mg}$ of calcium carbonate and vortex strongly for $30 \mathrm{~s}$. After the sonication, the sample was incubated at $200 \mathrm{rpm}$ for $30 \mathrm{~min}$ to be adsorbed into the calcium carbonate pores. To cross-link the adsorbed enzyme, $1.5 \mathrm{~mL}$ of $1 \%$ GA solution (diluted with $100 \mathrm{mM}$ phosphate buffer, $\mathrm{pH}$ 8.0) was added to the enzyme and calcium carbonate mixture samples. The sample was stored at room temperature for $60 \mathrm{~min}$ without any movement, and then incubated for $60 \mathrm{~min}$ at $200 \mathrm{rpm}$ to prepare cross-link between $\mathrm{CE}$ molecules. After that, $100 \mathrm{mM}$ Tris- $\mathrm{HCl}$ ( $\mathrm{pH}$ 8.0) was used to remove unreacted GA by centrifugation. The sample was consecutively washed thrice with buffer and stored in $100 \mathrm{mM}$ phosphate buffer ( $\mathrm{pH} \mathrm{8.0)}$ at $4^{\circ} \mathrm{C}$ until the next use. The amount of CE loaded into calcium carbonate was measured by BCA protein assay kit.

\section{Activity and Stability Measurement}

The activity of cross-linked CE in biomineral calcium carbonate microspheres was determined using the concentration of $p$-nitrophenol resulting from hydrolysis of $p$-nitrophenyl butyrate substrate dissolved in $N, N$-dimethylformamide. For activity measurement, $p$-nitrophenyl butyrate substrate was dissolved in $N, N$-dimethylformamide to prepare $10 \mathrm{mM}$ concentration, and then added to $100 \mathrm{mM}$ phosphate buffer ( $\mathrm{pH}$ 8.0) solution containing $0.042 \mathrm{mg}$ of cross-linked CE in $\mathrm{CaCO}_{3}$ to be $0.5 \mathrm{mM}$ of final substrate concentration. The enzyme reaction was performed by shaking for $12.5 \mathrm{~min}$ at $200 \mathrm{rpm}$ with $2.5 \mathrm{~min}$ intervals during the reaction. At each interval time, absorbance was measured at $400 \mathrm{~nm}$. The activity was calculated as the average of the slope values measured by absorbance per reaction time in proportion to the concentration of $p$-nitrophenol. After the measurement, the immobilized CE was washed five times with $100 \mathrm{mM}$ phosphate buffer $(\mathrm{pH} \mathrm{8.0)}$ and stored at room temperature.

The effect of $\mathrm{pH}$ on the activity of free and immobilized $\mathrm{CE}$ was performed over $\mathrm{pH}$ range 6.0-10.0 and at room temperature.
The effect of temperature on CE activity was carried out over 15$55^{\circ} \mathrm{C}$, at $\mathrm{pH}$ 8.0. The activity was measured according to the above experimental protocol. The results for $\mathrm{pH}$ and temperature are presented in a normalized form with the highest activity of each set assigned by the value of $100 \%$ activity.

The storage and recycling stability were measured using the above experimental protocol, and the relative activity at each time point was calculated as the percentage ratio of residual activity at each time to the initial activity of each sample. All samples were measured thrice for standard deviation. The standard deviation is represented by error bars in the figure.

\section{RESULTS AND DISCUSSION}

\section{Characteristics of the $\mathrm{CaCO}_{3}$ Microspheres}

The calcium carbonate microspheres were successfully synthesized based on the mineralization process as described in Figure 1A. The fabricated $\mathrm{CaCO}_{3}$ were successfully characterized using SEM with elemental analysis (EDS), PSA, FT-IR, XRD, BET, and BJH adsorption/desorption. When analyzed, Figure 2A shows the highly organized shape of calcium carbonate, as shown in the SEM image, well-dispersed spherical structure with the diameter of 4-6 $\mu \mathrm{m}$. The particle size analysis obtained by PSA, showing $5.5 \pm 1.8 \mu \mathrm{m}$ size distribution (Figure 2B), and EDS was used to confirm $\mathrm{CaCO}_{3}$ surface (Figure 2C). The XRD patterns of particle confirmed that well-crystallized mixed vaterite and aragonite phase, with their characteristic diffraction peaks of $2 \theta$

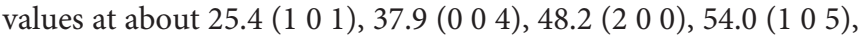
55.1 (2 11 1), and 62.9 (2 04 ), indicating nature of the calcium carbonate, were obtained (Figure 2D). Additionally, FT-IR spectrum indicated the typical $\mathrm{CaCO}_{3}$ peak coincident with the broad band at $1394 \mathrm{~cm}^{-1}$ ( $\mathrm{v} 3$ asymmetric $\mathrm{CO}_{3}{ }^{2-}$ ) and with the sharp band at $871 \mathrm{~cm}^{-1}$ ( $\mathrm{v} 2$ asymmetric $\mathrm{CO}_{3}{ }^{2-}$ ) (Figure 2E). The spherical calcium carbonate with mesoporous property is the key step to enzymes loading into the structured materials for efficient enzyme immobilization. Therefore, the $\mathrm{CaCO}_{3}$ microspheres are also expected to have pore sizes and volume enough for spaces without limitation. In fact, porous structure was confirmed through $\mathrm{BJH}$ analysis using the representative $\mathrm{N}_{2}$ adsorption/desorption data, shown in Table 1A. The BET surface area of the hybrid particles was $6.88 \mathrm{~m}^{2} \mathrm{~g}^{-1}$, and the fraction of vacant mesopores provided pore volume of $0.048 \mathrm{~m}^{2} / \mathrm{g}$, leading to entrap enzyme. In addition, average pore size from adsorption and average pore size from desorption of microspheres were $30.914 \mathrm{~nm}$ and $27.937 \mathrm{~nm}$, respectively (Table 1A). These unique structures are a suitable mesoporous material for enzyme immobilization, which allows facile biocatalysis.

\section{Enzyme Immobilization}

For enzyme immobilization, CE was prepared via a two-step process: enzyme adsorption and cross-linking into the prepared biomineralized calcium carbonate microspheres as described in Figure 1B. CE enzyme $(1.0 \mathrm{mg})$ was dissolved in $1.5 \mathrm{~mL}$ buffer solution under $200 \mathrm{rpm}$ shaking condition at room temperature. $\mathrm{CE}$ was adsorbed onto the exterior surface of the particles or 


\section{A \\ $\mathrm{CaCO}_{3}$ synthesis}
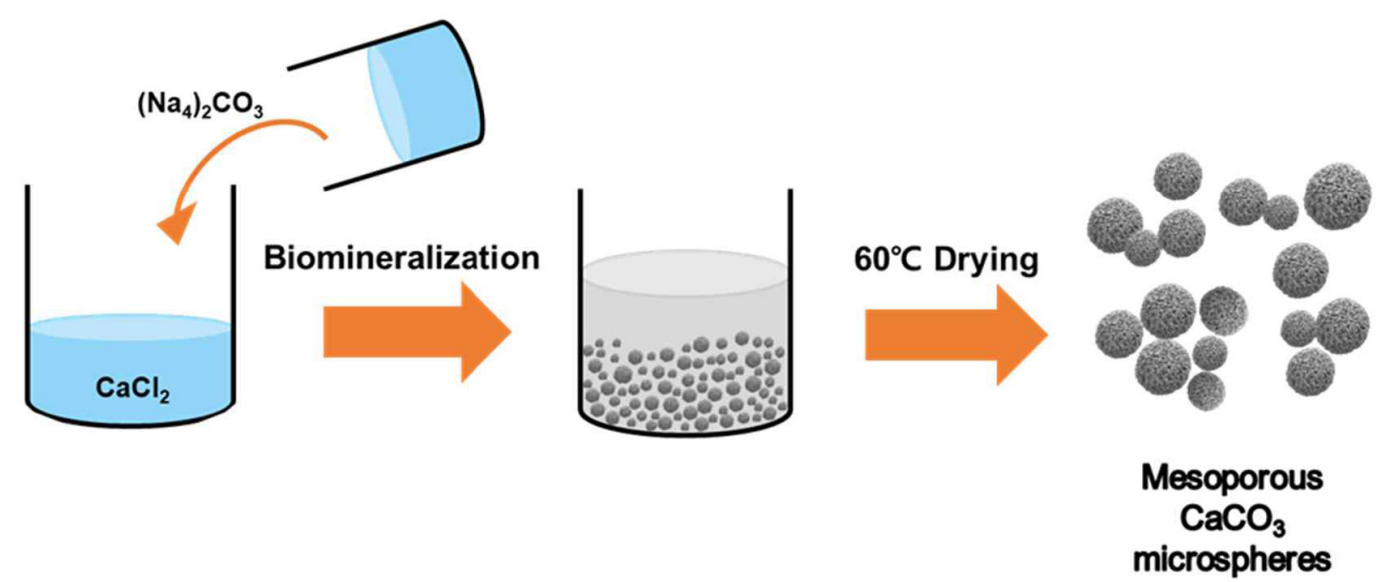

\section{B \\ CE Immobilization}
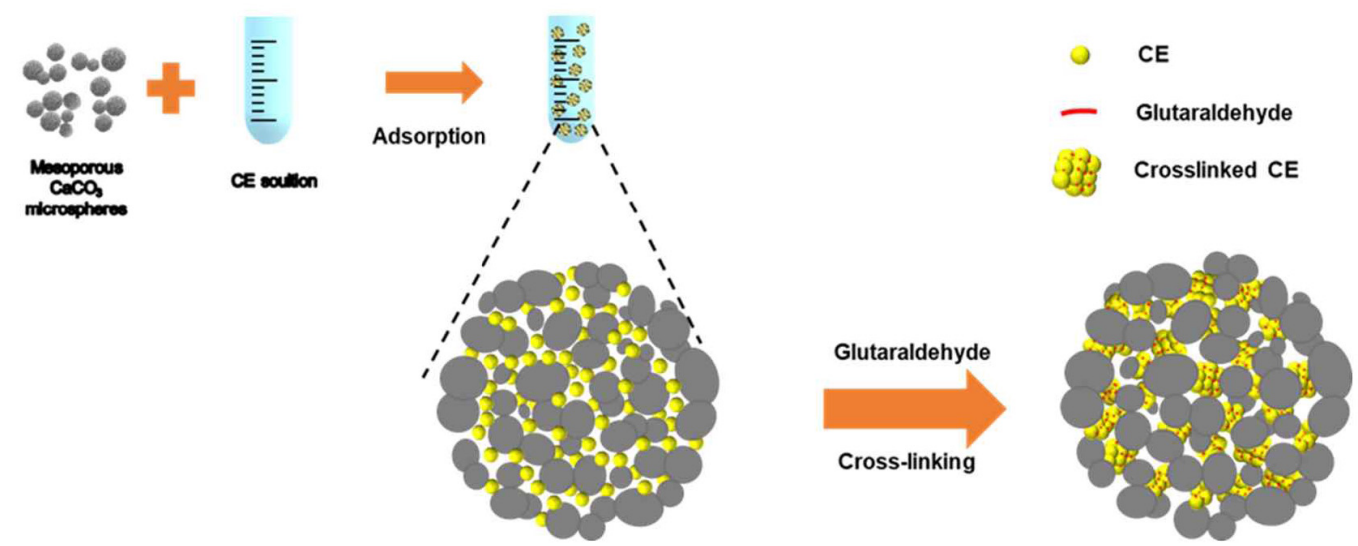

FIGURE 1 | Schematic illustrations of (A) $\mathrm{CaCO}_{3}$ microsphere preparation and (B) enzyme immobilization.

in the inter-particle space. After washing with $100 \mathrm{mM}$ sodium phosphate buffer ( $\mathrm{pH} 8.0$ ), enzyme adsorption was completed. To prevent the enzyme leaching in the calcium carbonate pores space, adsorbed enzyme molecules were cross-linked via GA chemical linker. The cross-linked CE improves loading quantity, loading efficiency, and prevents denaturation and release of enzymes, thus ensuring the stability of enzyme activity. The enzyme loading efficiency and loading amount are different depending on the concentration of enzyme and amount of calcium carbonate used as a carrier. Therefore, the experiment is optimized by keeping the amount of enzyme with $10 \mathrm{mg}$ of calcium carbonate microspheres. For measurement enzyme loading, BCA protein assay kit was used. About $0.2 \mathrm{mg}$ of CE was immobilized in $10 \mathrm{mg}$ of calcium carbonate microsphere during adsorption and washing steps. Unfortunately, CE loading could not be easily measured because cross-linked insoluble form of $\mathrm{CE}$ aggregates and cannot be used for protein assay kit. For the comparative studies, we assumed that enzymes are well retained within the mesopores of calcium carbonate upon GA treatment during immobilization. This means that about $20 \%$ of the enzyme is loaded during the adsorption and additional GA cross-linking process in the calcium carbonate pores.

\section{Characteristics of Immobilized Enzyme}

To characterize immobilized $\mathrm{CE}$ in the $\mathrm{CaCO}_{3}$ microspheres, we investigated $\mathrm{CE}$ catalyzed hydrolysis enzymatic reactions. The 


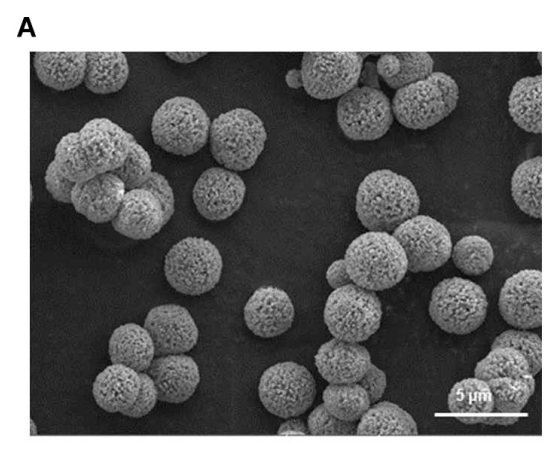

C

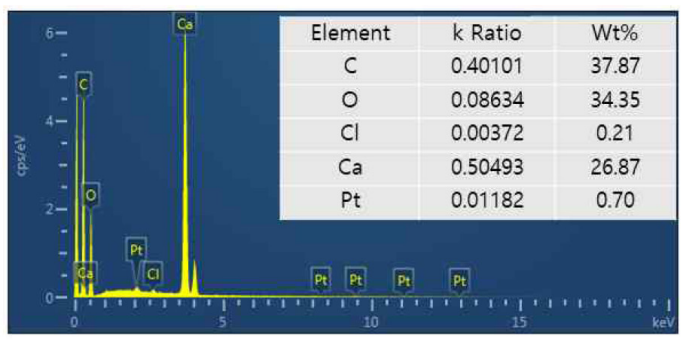

B

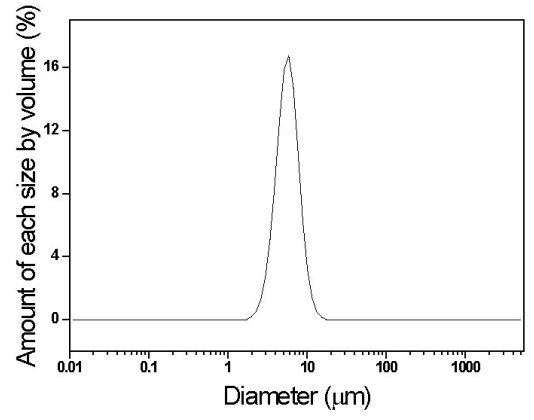

D

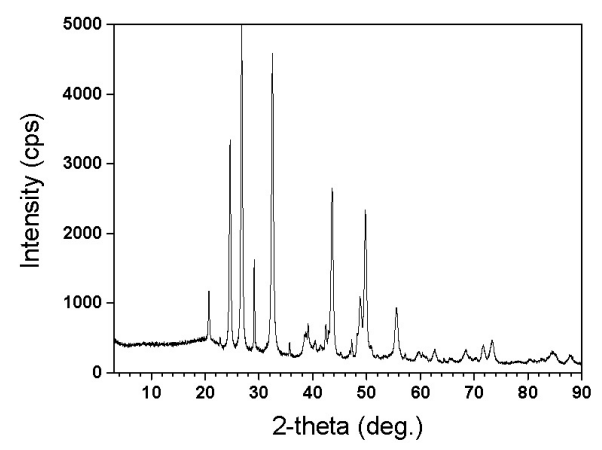

E

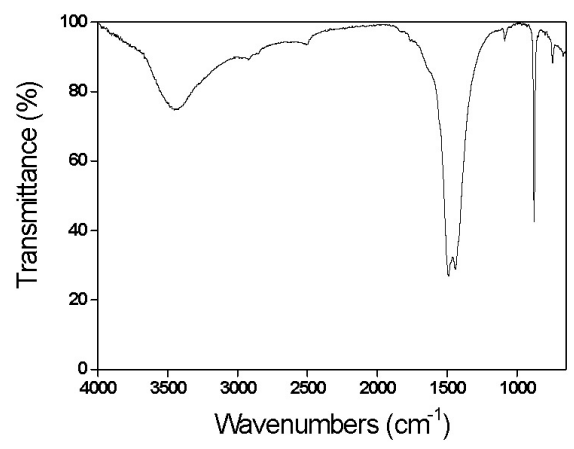

FIGURE 2 | (A) SEM images, (B) particle size distribution, (C) energy-dispersive X-ray spectroscopy (EDS), (D) XRD patterns, and (E) FT-IR spectrum of the prepared $\mathrm{CaCO}_{3}$ microspheres.

specific activities of free and cross-linked CE were 48.32 and $7.63 \mathrm{mM} \mathrm{min}{ }^{-1} \mathrm{mg}^{-1}$, respectively. The activity of free CE was $16 \%$ more than that of cross-linked CE (Table 1B), indicating that the flexibility of the enzyme may reduce low diffusion rate of the reactants and products, resulting in low activity values. Most enzymes immobilized using traditional methods displayed $<10 \%$ of specific activity retention (Zhang et al., 2011); therefore, $16 \%$ represents a high retention of specific activity along with maintaining this activity and preserving stability, thus preventing the denaturation and autolysis of CE (Table 1B).
To investigate efficiency of immobilization, the stability of free and cross-linked $\mathrm{CE}$ at different $\mathrm{pH}$ and temperature conditions was examined. The effect of $\mathrm{pH}$ effect on the activity was examined in the range of $6.0-10.0$ at $25^{\circ} \mathrm{C}$, and the highest $\mathrm{CE}$ activity was observed at $\mathrm{pH}$ 8.0. During the $\mathrm{pH}$ study, immobilized CE was more stable compared to free CE, indicating that enzyme activity is preserved after immobilization (Figure 3A). These results could probably be attributed to the stabilization of enzymes resulting from its multipoint attachments on the surface of CE via GA treatment. Furthermore, 
TABLE 1 | Characteristics of (A) $\mathrm{CaCO}_{3}$ microspheres, and (B) free $\mathrm{CE}$ and cross-linked CE (A).

(A)

\begin{tabular}{|c|c|c|c|c|}
\hline & $\begin{array}{l}S_{\mathrm{BET}} \\
\left(\mathrm{m}^{2} / \mathrm{g}\right)\end{array}$ & $\begin{array}{c}V \\
\left(\mathrm{~cm}^{3} / \mathrm{g}\right)\end{array}$ & $\begin{array}{c}d_{\text {ad }} \text { (average) } \\
(\mathrm{nm})\end{array}$ & $\begin{array}{c}d_{\mathrm{de}} \text { (average) } \\
(\mathrm{nm})\end{array}$ \\
\hline $\mathrm{CaCO}_{3}$ microspheres & 6.888 & 0.048 & 30.914 & 27.937 \\
\hline
\end{tabular}

(B)

\begin{tabular}{lccc}
\hline Sample & $\begin{array}{c}\text { Specific activity } \\
\left(\mathbf{m M ~} \mathbf{~ i n}^{-\mathbf{1}} \mathbf{~ m g}^{-\mathbf{1}}\right)\end{array}$ & $\begin{array}{c}\boldsymbol{K}_{\mathbf{m}} \\
\mathbf{( m M )}\end{array}$ & $\begin{array}{c}\boldsymbol{V}_{\text {max }} \\
\left(\mathbf{m M ~} \mathbf{~ m i n}^{-\mathbf{1}}\right)\end{array}$ \\
\hline Free CE & 48.32 & $0.25 \pm 0.02$ & $2.82 \pm 0.13$ \\
Cross-linked CE & 7.63 & $0.94 \pm 0.25$ & $0.82 \pm 0.16$
\end{tabular}

$S_{B E T}$ is the BET surface area; $V$ is the total pore volume; pore size, $d_{a d}$ and $d_{d e}$ were calculated using the BJH (Barett-Joyner-Halenda) method. the microenvironment of the immobilized enzyme in inorganic $\mathrm{CaCO}_{3}$ microspheres might lead to the displacements in the $\mathrm{pH}$ activity profile arising from electrostatic interactions with the negative charged hydrophobic $\mathrm{CaCO}_{3}$ surfaces (Vescovi et al., 2016). During temperature profiling in the temperature range of $15-55^{\circ} \mathrm{C}$, at $\mathrm{pH} 8.0$, compared to free $\mathrm{CE}$, immobilized $\mathrm{CE}$ was found to be more stable. At $55^{\circ} \mathrm{C}$, the activity of free $\mathrm{CE}$ reduced by $62 \%$, whereas cross-linked $\mathrm{CE}$ exhibited $94 \%$ activity (Figure 3B). It shows that immobilized CE could withstand higher temperature conditions compared to free CE and temperature profile of immobilized $\mathrm{CE}$ is broader than free CE activity at all temperatures. It was confirmed that the abnormality was maintained, and the immobilization resulted in an increase in the resistance of the $\mathrm{CE}$ to $\mathrm{pH}$ and temperature. All range of $\mathrm{pH}$ and temperature, the activity of immobilized CE was higher than that of free CE (Figure 3), indicating that
A

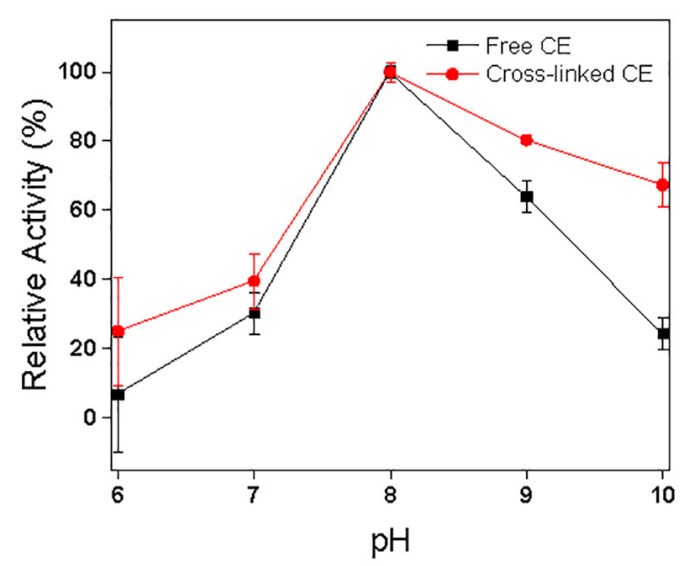

C

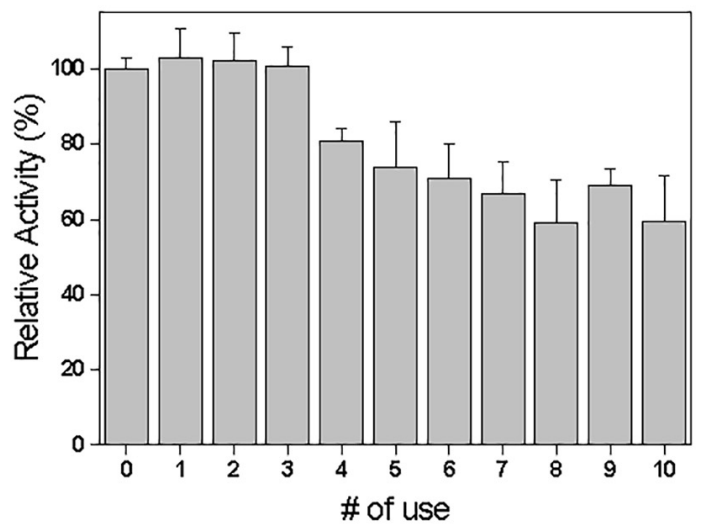

B
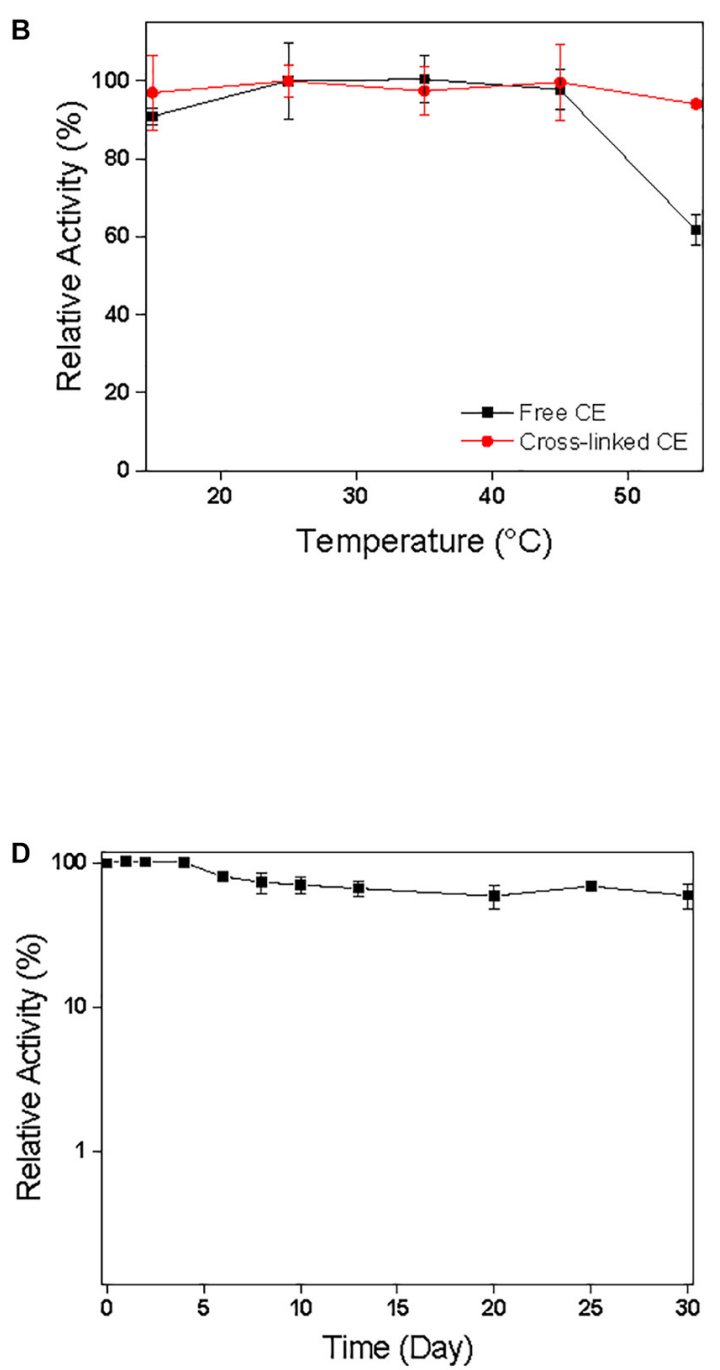

FIGURE 3 | Effect of (A) pH and (B) temperature on enzyme activity in comparison of free CE and cross-linked CE. The results were normalized with the highest value of each set being assigned the value of $100 \%$ activity. (C) Recycling and (D) Storages stability of cross-linked CE. The relative activity was calculated based on the initial activity value of $100 \%$. 
enzyme activity is preserved after immobilization. The resistance to temperature and $\mathrm{pH}$ was increased due to the effect of crosslinking immobilization strategy in the pores of the calcium carbonate microspheres.

\section{Storage and Recycling Stability of Immobilized Enzyme}

The stability of immobilized CE was checked by measuring time-dependent absorbance change in $p$-nitrophenol production by $\mathrm{CE}$ catalyzed reaction when each sample was incubated in $100 \mathrm{mM}$ sodium phosphate buffer $(\mathrm{pH}$ 8.0) under shaking at $200 \mathrm{rpm}$ (Figures 3C,D). In our previous study, free CE activity retained $<1 \%$ residual activity within a week. Figures 3 C,D shows the results of the reuse and storage stability of the immobilized enzyme in the pores of biomineralized calcium carbonate microspheres. The relative activity of the cross-linked $\mathrm{CE}$ is defined as a ratio to the initial activity value; therefore, the initial activity value is assumed to be $100 \%$. To investigate the reuse and storage stability of the enzyme, after measurement of enzyme activity, the immobilized enzyme was washed five times with $100 \mathrm{mM}$ phosphate buffer ( $\mathrm{pH} \mathrm{8.0)}$ and stored at room temperature. As shown in Figures 3C, after reusing the enzyme 10 times, $>60 \%$ of the activity was maintained depending upon the initial activity value. Therefore, cross-linked CE was able to preserve high activity and stability compared to the initial activity value even after repeated use. In addition, during the storage period of 30 days (Figure 3D), immobilized CE maintained high activity relative to the initial activity value and maintained stability. The high stability of cross-linked CE can be preserved because cross-linking prevents the release of enzymes, which are adsorbed into the pores of calcium carbonate, and inhibits the denaturation of the enzyme structure by inducing multiplepoint chemical linkages. The enzyme stabilization attained can be explained by the "ship-in-a-bottle" mechanism. The crosslinking of the enzyme prevents its leaching through the smaller bottleneck pore structure of the mesoporous calcium carbonate particles. The success with highly stable immobilized enzyme in the $\mathrm{CaCO}_{3}$ has opened up a great potential for a variety of enzymatic synthetic reactions to be practically realized based on this biomineral based process design.

\section{REFERENCES}

Abalymov, A., Van Poelvoorde, L., Atkin, V., Skirtach, A. G., Konrad, M., and Parakhonskiy, B. (2020). Alkaline phosphatase delivery system based on calcium carbonate carriers for acceleration of ossification. ACS Appl. Bio Mater. 3, 2986-2996. doi: 10.1021/acsabm.0c00053

Barbosa, O., Ortiz, C., Berenguer-Murcia, A., Torres, R., Rodrigues, R. C., and Fernandez-Lafuente, R. (2014). Glutaraldehyde in bio-catalysts design: a useful crosslinker and a versatile tool in enzyme immobilization. RSC Adv. 4, 15831600. doi: 10.1039/c3ra45991h

Binevski, P. V., Balabushevich, N. G., Uvarova, V. I., Vikulina, A. S., and Volodkin, D. (2019). Bio-friendly encapsulation of superoxide dismutase into vaterite $\mathrm{CaCO} 3$ crystals, Enzyme activity, release mechanism, and perspectives for ophthalmology. Colloid. Surf. B 181, 437-449. doi: 10.1016/j.colsurfb.2019. 05.077

Cantone, S., Ferrario, V., Corici, L., Ebert, C., Fattor, D., Spizzo, P., et al. (2013). Efficient immobilisation of industrial biocatalysts: criteria and constraints for

\section{CONCLUSION}

Biomineral calcium carbonate was fabricated and well characterized using XRD, TEM, SEM, EDS, and BET surface area, pore size, and volume of adsorption and desorption pores. CE from Rhizopus oryzae was successfully immobilized by adsorption, followed by cross-linking in the biomineral calcium carbonate pores. During immobilization, $20 \%$ of the CE enzyme was loaded in the pores of calcium carbonate, and $16 \%$ of specific activity was maintained compare to free CE. The enzyme retained $>60 \%$ of relative enzyme activity even after 10 reuses, when stored for 30 days at room temperature, indicating high recycling and storage stability. Therefore, this method, which successfully used natural calcium carbonate to immobilize enzyme and confirmed its stability as a biological resource, showed the possibility of applying another enzyme. It can be used as a new functional material.

\section{DATA AVAILABILITY STATEMENT}

All datasets presented in this study are included in the article/supplementary material.

\section{AUTHOR CONTRIBUTIONS}

$\mathrm{EH}$ and JL contributed to conception and design of the study. CL performed the experiments and analyzed the data. EJ wrote sections of the manuscript. CL wrote the first draft of the manuscript. EH and JL finalized the manuscript. All authors contributed to manuscript revision and read and approved the submitted version.

\section{FUNDING}

This work was supported by the Dong-A University Research Fund.

the selection of organic polymeric carriers and immobilisation methods. Chem Soc. Rev. 42, 6262-6276. doi: 10.1039/c3cs35464d

Datta, S., Christena, L. R., and Rajaram, Y. R. S. (2013). Enzyme immobilization: an overview on techniques and support materials. 3 Biotech 3, 1-9. doi: 10.1007/ s13205-012-0071-7

Donatan, S., Yashchenok, A., Khan, N., Parakhonskiy, B., Cocquyt, M., Pinchasik, B.-E., et al. (2016). Loading capacity versus enzyme activity in anisotropic and spherical calcium carbonate microparticles. ACS Appl. Mater. Interf. 8, 14284-14292. doi: 10.1021/acsami.6b03492

Fakhrullin, R. F., and Minullina, R. T. (2009). Hybrid cellular-inorganic core-shell microparticles: encapsulation of individual living cells in calcium carbonate microshells. Langmuir 25, 6617-6621. doi: 10.1021/la901395z

Gower, L. B. (2008). Biomimetic model systems for investigating the amorphous precursor pathway and its role in biomineralization. Chem. Rev. 108, 45514627. doi: 10.1021/cr800443h

Hanefeld, U., Gardossi, L., and Magner, E. (2009). Understanding enzyme immobilisation. Chem. Soc. Rev. 38, 453-468. doi: 10.1039/b711564b 
Heck, T., Faccio, G., Richter, M., and Thöny-Meyer, L. (2013). Enzyme-catalyzed protein crosslinking. Appl. Microbiol. Biotechnol. 97, 461-475. doi: 10.1007/ s00253-012-4569-z

Hwang, E. T., Gang, H., Chung, J., and Gu, M. B. (2012a). Carbonic anhydrase assisted calcium carbonate crystalline composites as a biocatalyst. Green Chem. 14, 2216-2220. doi: 10.1039/c2gc35444f

Hwang, E. T., Gang, H., and Gu, M. B. (2013). CO2 bioconversion using carbonic anhydrase (CA): effects of PEG rigidity on the structure of bio-mineralized crystal composites. J. Biotechnol. 168, 208-211. doi: 10.1016/j.jbiotec.2013. 06.024

Hwang, E. T., and Gu, M. B. (2013). Enzyme stabilization by nano/microsized hybrid materials. Eng. Life Sci 13, 49-61. doi: 10.1002/elsc.201100225

Hwang, E. T., Lee, B., Zhang, M., Jun, S.-H., Shim, J., Lee, J., et al. (2012b). Immobilization and stabilization of subtilisin Carlsberg in magneticallyseparable mesoporous silica for transesterification in an organic solvent. Green Chem. 14, 1884-1887. doi: 10.1039/c2gc35559k

Iyer, P. V., and Ananthanarayan, L. (2008). Enzyme stability and stabilizationAqueous and non-aqueous environment. Process Biochem. 43, 1019-1032. doi: 10.1016/j.procbio.2008.06.004

Jesionowski, T., Zdarta, J., and Krajewska, B. (2014). Enzyme immobilization by adsorption: a review. Adsorption 20, 801-821. doi: 10.1007/s10450-014-9623-y

Kim, M. I., Kim, J., Lee, J., Jia, H., Na, H. B., Youn, J. K., et al. (2007). Crosslinked enzyme aggregates in hierarchically-ordered mesoporous silica: a simple and effective method for enzyme stabilization. Biotechnol. Bioeng. 96, 210-218. doi: 10.1002/bit.21107

Li, L.-L., and Wang, H. (2013). Enzyme-coated mesoporous silica nanoparticles as efficient antibacterial agents in vivo. Adv. Health. Mater. 2, 1351-1360. doi: 10.1002/adhm.201300051

Mateo, C., Palomo, J. M., Fernandez-Lorente, G., Guisan, J. M., and FernandezLafuente, R. (2007). Improvement of enzyme activity, stability and selectivity via immobilization techniques. Enzyme Microb. Technol. 40, 1451-1463. doi: 10.1016/j.enzmictec.2007.01.018

Muderrisoglu, C., Saveleva, M., Abalymov, A., Van Der Meeren, L., Ivanova, A., Atkin, V., et al. (2018). Nanostructured biointerfaces based on bioceramic calcium carbonate/hydrogel coatings on titanium with an active enzyme for stimulating osteoblasts growth. Adv. Mater. Interf. 5:1800452. doi: 10.1002/ admi.201800452

Rodriguez-Abetxuko, A., Sánchez-Dealcázar, D., Muñumer, P., and Beloqui, A. (2020). Tunable polymeric scaffolds for enzyme immobilization. Front. Bioeng. Biotechnol. 8:830. doi: 10.3389/fbioe.2020.00830

Roth, R., Schoelkopf, J., Huwyler, J., and Puchkov, M. (2018). Functionalized calcium carbonate microparticles for the delivery of proteins. Eur. J. Pharm. Biopharm. 122, 96-103. doi: 10.1016/j.ejpb.2017.10.012
Schoemaker, H. E., Mink, D., and Wubbolts, M. G. (2003). Dispelling the mythsbiocatalysis in industrial synthesis. Science 299:1694. doi: 10.1126/science. 1079237

Vescovi, V., Kopp, W., Guisán, J. M., Giordano, R. L. C., Mendes, A. A., and Tardioli, P. W. (2016). Improved catalytic properties of Candida antarctica lipase B multi-attached on tailor-made hydrophobic silica containing octyl and multifunctional amino- glutaraldehyde spacer arms. Process Biochem. 51, 2055-2066. doi: 10.1016/j.procbio.2016.09.016

Wang, X., Shi, J., Li, Z., Zhang, S., Wu, H., Jiang, Z., et al. (2014). Facile onepot preparation of chitosan/calcium pyrophosphate hybrid microflowers. ACS Appl. Mater. Interf. 6, 14522-14532. doi: 10.1021/am503787h

Wang, Y., and Caruso, F. (2004). Enzyme encapsulation in nanoporous silica spheres. Chem. Commun. 13, 1528-1529. doi: 10.1039/b403871a

Wu, X., Hou, M., and Ge, J. (2015). Metal-organic frameworks and inorganic nanoflowers: a type of emerging inorganic crystal nanocarrier for enzyme immobilization. Catal. Sci. Technol. 5, 5077-5085. doi: 10.1039/c5cy01181g

Xia, H., Li, N., Zhong, X., and Jiang, Y. (2020). Metal-organic frameworks: a potential platform for enzyme immobilization and related applications. Front. Bioeng. Biotechnol. 8:695. doi: 10.3389/fbioe.2020.00695

Xu, C., Lei, C., and Yu, C. (2019). Mesoporous silica nanoparticles for protein protection and delivery. Front. Chem. 7:290. doi: 10.3389/fchem.2019.00290

Zdarta, J., Meyer, A. S., Jesionowski, T., and Pinelo, M. (2018). A general overview of support materials for enzyme immobilization: characteristics, properties, practical utility. Catalysts 8:92. doi: 10.3390/catal8020092

Zhang, Y., Gao, F., Zhang, S. P., Su, Z. G., Ma, G. H., and Wang, P. (2011). Simultaneous production of 1,3-dihydroxyacetone and xylitol from glycerol and xylose using a nanoparticle-supported multi-enzyme system with in situ cofactor regeneration. Bioresour. Technol. 102, 1837-1843. doi: 10.1016/j. biortech.2010.09.069

Zucca, P., and Sanjust, E. (2014). Inorganic materials as supports for covalent enzyme immobilization: methods and mechanisms. Molecules 19, 14139-14194. doi: 10.3390/molecules 190914139

Conflict of Interest: The authors declare that the research was conducted in the absence of any commercial or financial relationships that could be construed as a potential conflict of interest.

Copyright (c) 2020 Lee, Jin, Lee and Hwang. This is an open-access article distributed under the terms of the Creative Commons Attribution License (CC BY). The use, distribution or reproduction in other forums is permitted, provided the original author(s) and the copyright owner(s) are credited and that the original publication in this journal is cited, in accordance with accepted academic practice. No use, distribution or reproduction is permitted which does not comply with these terms. 